\title{
Comparison of Long Term Prognosis between Carotid Endarterectomy versus Stenting; A Korean Population-Based Study Using National Insurance Data
}

\author{
Kwon-Duk Seo, $\mathrm{MD}^{1}$, Kyung-Yul Lee, $\mathrm{MD}, \mathrm{PhD}^{2}$, Sang Hyun Suh, MD, PhD \\ ${ }^{1}$ Department of Neurology, National Health Insurance Service Ilsan Hospital, Goyang, Korea \\ ${ }^{2}$ Department of Neurology, Gangnam Severance Hospital, Yonsei University College of Medicine, Seoul, Korea \\ ${ }^{3}$ Department of Radiology, Gangnam Severance Hospital, Yonsei University College of Medicine, Seoul, Korea
}

Purpose: Although carotid endarterectomy (CEA) is recommended as a treatment for carotid stenosis rather than carotid artery stenting (CAS), CAS has been preferred in Korea. The aim of this study was to analyze long-term outcomes after CAS compared with CEA using Korean nationwide insurance data.

Materials and Methods: We obtained all data from the nationwide database of the Health Insurance Review \& Assessment Service (HIRA) during the study period using several codes regarding the procedure or operation. We included the HIRA data, which included at least oneyear follow-up after the procedures. The outcomes associated with both procedures were death, recurrence of ischemic stroke, and admission for cerebral hemorrhage.

Results: A total of 16,065 eligible patients who were treated with CAS or CEA between 1 January 2007 and 31 December 2016 were analyzed. The number of patients with CAS and CEA was 12,173 (75.8\%) and 3,892 (24.2\%), respectively. 8,976 patients (55.9\%) were classified as symptomatic patients. CAS was associated with a higher risk of all-cause mortality (adjusted hazard ratio [HR], 1.282; 95\% confidence interval [CI], 1.173-1.400). The adjusted rates for recurrent ischemic stroke and cerebral hemorrhage between CAS versus CEA were $24.9 \%$ versus $15.9 \%(\mathrm{HR}, 1.474 ; 95 \% \mathrm{Cl}, 1.325-1.639)$ and $1.5 \%$ versus $0.9 \%$ (HR, 2.026; 95\% Cl, 1.322-3.106), respectively. In young symptomatic patients, there was no statistically significant difference in all-cause mortality and cardiovascular death between CAS and CEA.

Conclusion: Our study using Korean nationwide insurance data demonstrated similar results to previous studies. Until further evidence of CAS is established through prospective studies, CAS should be performed in selected patients according to current guidelines.

Key Words: Carotid stenosis; Endarterectomy; Stents; Population health

\section{Correspondence to:} Sang Hyun Suh, MD, PhD

Department of Radiology, Gangnam Severance Hospital, Yonsei University College of Medicine, 211 Eonju-ro, Gangnam-gu, Seoul 06273, Korea Tel: $+82-2-2019-3510$

Fax: +82-2-3462-5472

E-mail:suhsh11@yuhs.ac

Received: June 5, 2019

Revised: July 25, 2019

Accepted: August 12, 2019
Copyright $\odot 2019$ Korean Society of Interventional Neuroradiology

This is an Open Access article distributed under the terms of the Creative Commons Attribution Non-Commercial License (http://creativecommons.org/licenses/by-nc/3.0) which permits unrestricted non-commercial use, distribution, and reproduction in any medium, provided the original work is properly cited. 


\section{INTRODUCTION}

Carotid artery stenosis is known to cause about 15\% of ischemic stroke.' Carotid endarterectomy (CEA) is recommended more often than carotid artery stenting (CAS) for the treatment of severe carotid stenosis according to European guidelines in 2017. ${ }^{2}$ CAS is indicated as an alternative to CEA for symptomatic patients younger than 70 years. ${ }^{2,3}$ Also, it is recommended that CAS be performed instead of CEA if the patient has a high-risk anatomical structure or has comorbidities listed in the guidelines of various countries. ${ }^{4}$

Unlike in Europe and America, CAS has been preferred in Korea, because of its non-invasiveness and the limited number of hospitals capable of performing CEA. As a result, there has been a report that CAS is performed three times more frequently than CEA every year in Korea. ${ }^{5}$ In most studies evaluating patient outcomes for those receiving carotid revascularization, there were more patients who received CEA than CAS, except for randomized clinical trials. ${ }^{6}$ There was no difference in long-term mortality in the randomized clinical trials, but the prognosis of patients with CEA was better in the observational study?

In this study, we investigated the long-term prognosis of patients with carotid revascularization in Korea where different rates of treatment patterns are present.

\section{MATERIALS AND METHODS}

\section{Participants}

In Korea, all national citizens are required to enroll in the Korean National Health Insurance Service (KNHIS). The dataset is used as the source of research data came from the nationwide claim database of KNHIS. We selected the KNHIS database entries between January 1, 2007 and December 31, 2016, which fulfilled at least one-year follow-up after the CAS or CEA. KNHIS uses the Korean Classification of Diseases (KCD), which is similar to the International Classification of Diseases (ICD), to provide consistent diagnostic codes. The data of the KNHIS include codes for procedure or operation, and can be classified by specific codes, such as M6602 for CAS and O0226, O0227, and O2066 for CEA. Research participants were selected by including cases with KCD codes of 165.2 and 163 related to carotid artery stenosis, and cerebral infarction as claim codes in principal and minor diagnoses. Participants were selected using several codes for CAS and
CEA.

This study was conducted to determine the cerebrovascular events after treatment. The risk factors associated with cerebrovascular disease of the individuals were identified by using KCD codes according to the proposed algorithms. ${ }^{8,9}$ Symptomatic patients were defined as those who had been hospitalized with cerebral infarction within 180 days prior to carotid revascularization. ${ }^{10}$ The time of death was obtained from the KNHIS database and the cause of death was obtained from Statistics Korea. Among the causes of death, cardiovascular disease was identified through 100-199 codes until December 31, 2016. The recurrence of cerebral infarction was defined as a case of readmission with KCD code 163 as the principal diagnosis after at least 28 days of carotid revascularization. The occurrence of cerebral hemorrhage was defined as the case of readmission with KCD codes 160, 161, and 162 as the principal diagnosis. ${ }^{11}$ The event-free survival time was defined as the time from the first treatment to re-admission of ischemic stroke, cerebral hemorrhage, death, or the end of the study, which was December 31, 2017. For patients who received more than one treatment during the study period, only the first treatment was analyzed in the study.

Patients treated for disease other than atherosclerotic carotid stenosis were excluded (carotid artery dissection, aortic dissection, cerebral artery dissection, unruptured cerebral aneurysm, and Takayasu arteritis). Patients under 45 years of age were excluded to include only those patients treated with carotid stenosis due to atherosclerosis. We excluded the patients treated in 2007 for a year to select patients who received only one treatment during the study period (washout period) (Fig. 1).

This study was conducted after obtaining approval from the Institutional Review Board at Wonkwang University Sanbon Hospital (IRB No. WMCSB 201711-118).

\section{Statistics}

Data were analyzed using SAS, version 9.4 (SAS Inc., Cary, NC, USA). In order to examine the difference in demographic data between patients treated with CAS and CEA, the Student's t-test was used for continuous variables, and chisquare was used for categorical variables. Kaplan-Meier survival analysis was performed for the time elapsed from the time to treat to death or re-admission. The hazard ratio (HR) was calculated using the Cox proportional hazards model. A 95\% confidence interval (Cl) and a P-value $<0.05$ were used 
for to indicate statistical significance.

\section{RESULTS}

A total of 16,065 eligible patients who were treated with CAS or CEA were analyzed in the validation data set. The mean follow-up period was 62 months (range, 12-120). There were 12,173 patients (75.8\%) who received CAS (CAS group) and 3,892 patients (24.2\%) received CEA (CEA group). Eight thousand nine hundred seventy six patients (55.9\%) were classified as symptomatic patients. The proportion of symptomatic patients was higher in patients receiving CAS (60.2\%) than CEA (42.4\%). The mean age was higher in the CAS group than CEA group ( $70.17 \pm 8.05$ vs. $68.99 \pm 7.80)$. Hypertension, diabetes mellitus, dyslipidemia, and ischemic heart disease were more prevalent in the CEA group. Atrial fibrillation and renal failure showed no significant difference between the two groups (Table 1). This difference in demographic data was similar when analyzed separately for symptomatic pa-
Table 1. Clinical characteristics of two groups

\begin{tabular}{lccc}
\hline & CAS $(\mathrm{n}=12,173)$ & CEA $(\mathrm{n}=3,892)$ & P-value \\
\hline Male & $9,976(81.95)$ & $3,246(83.40)$ & 0.0391 \\
Age & $70.17 \pm 8.05$ & $68.99 \pm 7.80$ & $<0.001$ \\
Hypertension & $7,471(61.37)$ & $2,674(68.71)$ & $<0.001$ \\
Diabetes mellitus & $4,724(38.81)$ & $1,618(41.57)$ & 0.0021 \\
Dyslipidemia & $5,347(43.93)$ & $1,824(46.87)$ & 0.0013 \\
Atrial fibrillation & $446(3.66)$ & $169(4.34)$ & 0.0549 \\
Ischemic heart & $2,934(24.10)$ & $1,013(26.03)$ & 0.0152 \\
$\quad$ disease & $251(2.06)$ & $61(1.57)$ & 0.0516 \\
Renal failure & $7,327(60.20)$ & $1,649(42.40)$ & $<0.001$ \\
\hline Symptomatic & & &
\end{tabular}

Values are presented as mean \pm standard deviation or number (\%). CAS, carotid artery stenting; CEA, carotid endarterectomy.
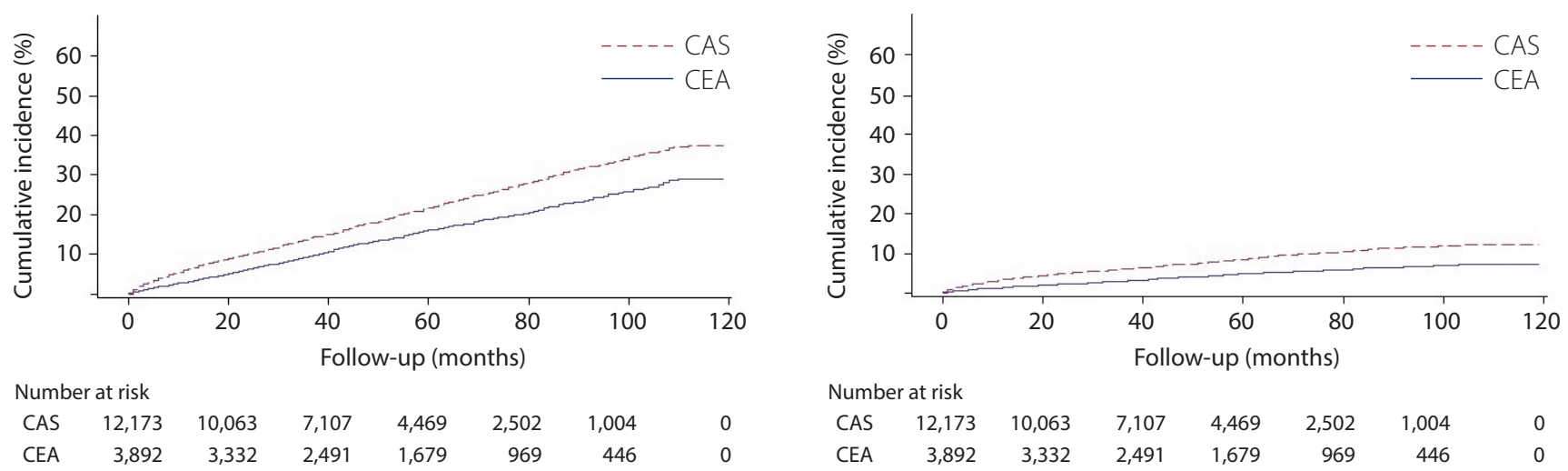

A
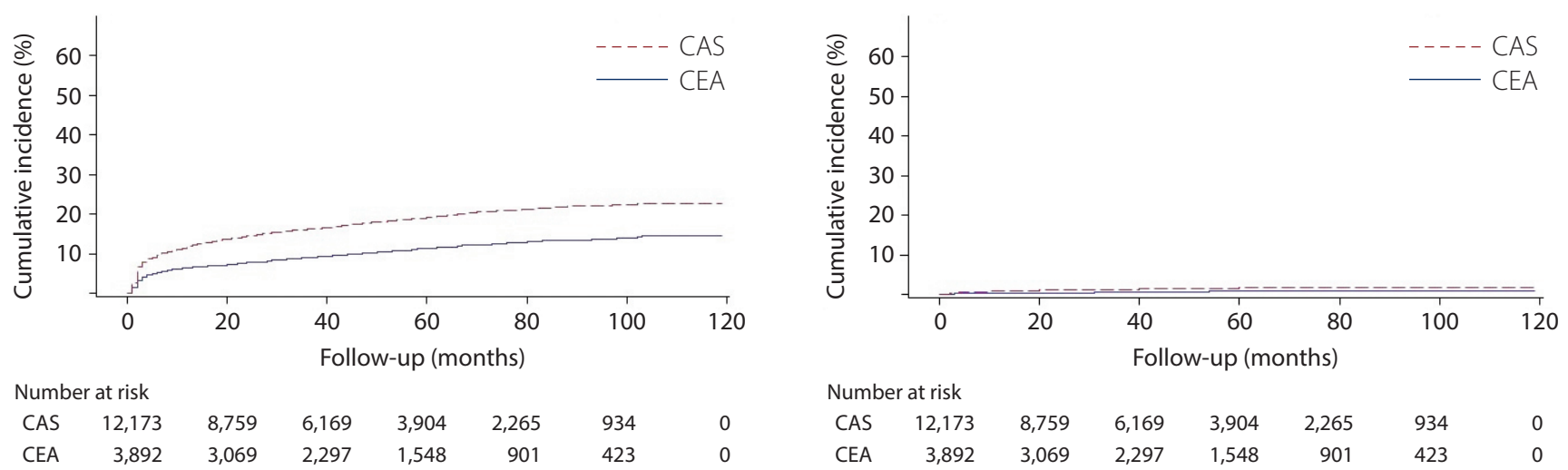

C

Fig. 1. Kaplan-Meier estimates of cumulative incidence of major outcomes. (A) All-cause mortality after treatment. (B) Cardiovascular death after treatment. (C) Ischemic stroke for $>28$ days after treatment. (D) Cerebral hemorrhage for $>28$ days after treatment. The numbers below the graph are the numbers of patients in each group who were event free and still at risk during follow-up period. CAS, carotid artery stenting; CEA, carotid endarterectomy. 
tients.

The statistically significant factors associated with all-cause mortality were chronic renal failure and old age. CAS was also associated with all-cause mortality, but the HR was 1.282 (95\% Cl, 1.173-1.400) and lower than other factors (Table 2). Patients treated with CAS had an overall higher risk for cardiovascular death ( $\mathrm{HR}, 1.569 ; 95 \% \mathrm{Cl}, 1.338-1.841)$ or ischemic stroke (HR, 1.474; 95\% Cl, 1.325-1.639). However, other factors were more significantly related to the cardiovascular death or ischemic stroke. The risk factors for cardiovascular death were old age, chronic renal failure, atrial fibrillation, symptomatic case, and CAS. The risk factors for readmission of ischemic stroke were symptomatic case, CAS, old age, and atrial fibrillation (Table 3). Patients treated with CAS had also higher risk for cerebral hemorrhage (HR, 2.026; 95\% Cl, 1.322-3.106), but atrial fibrillation ( $\mathrm{HR}, 2.505 ; 95 \% \mathrm{Cl}, 1.495-4.198)$ and renal failure ( $\mathrm{HR}, 2.771 ; 95 \% \mathrm{Cl}, 1.357-5.656)$ were more significantly related to the cerebral hemorrhage.

Table 2. Multivariate Cox regression analysis of overall HR related to the all-cause mortality

\begin{tabular}{|c|c|c|c|c|}
\hline Variable & Dead & Alive & $\mathrm{HR}(95 \% \mathrm{Cl})$ & P-value \\
\hline Treatment & & & & $<0.0001$ \\
\hline CAS & 2,607 (21.4) & $9,566(78.6)$ & $1.282(1.173-1.400)$ & \\
\hline CEA & $633(16.3)$ & $3,259(83.7)$ & 1 & \\
\hline Gender & & & & $<0.0001$ \\
\hline Male & 2,755 (20.8) & $10,467(79.2)$ & $1.351(1.226-1.488)$ & \\
\hline Female & $485(17.1)$ & $2,358(81.9)$ & 1 & \\
\hline Age & & & & $<0.0001$ \\
\hline$\geq 80$ years & $582(35.5)$ & $1,056(64.5)$ & $2.590(2.362-2.839)$ & \\
\hline$<80$ years & 2,658 (18.4) & $11,769(81.6)$ & 1 & \\
\hline Hypertension & & & & 0.0435 \\
\hline Yes & 1,997 (19.7) & $8,148(80.3)$ & $0.928(0.864-0.998)$ & \\
\hline No & $1,243(21.0)$ & $4,677(79.0)$ & & \\
\hline Diabetes mellitus & & & & 0.0286 \\
\hline Yes & 1,295 (20.4) & $5,047(79.6)$ & $1.082(1.008-1.162)$ & \\
\hline No & $1,945(20.0)$ & $7,778(80.0)$ & 1 & \\
\hline Dyslipidemia & & & & $<0.0001$ \\
\hline Yes & $1,129(15.7)$ & $6,042(84.3)$ & $0.739(0.687-0.794)$ & \\
\hline No & $2,111(23.7)$ & 6,783 (76.3) & 1 & \\
\hline Atrial fibrillation & & & & $<0.0001$ \\
\hline Yes & $167(27.2)$ & $448(72.8 \%)$ & $1.465(1.251-1.716)$ & \\
\hline No & $3,073(19.9)$ & $12,377(80.1)$ & 1 & \\
\hline Ischemic heart disease & & & & 0.2774 \\
\hline Yes & $798(20.2)$ & $3,149(79.8)$ & & \\
\hline No & $2,442(20.2)$ & $9,676(79.8)$ & & \\
\hline Chronic renal failure & & & & $<0.0001$ \\
\hline Yes & $122(39.1)$ & $190(60.9)$ & $2.598(2.139-3.156)$ & \\
\hline No & $3,118(19.8)$ & $12,635(80.2)$ & 1 & \\
\hline Symptomatic & & & & $<0.0001$ \\
\hline Yes & $2,157(24.0)$ & $6,819(76.0)$ & $1.530(1.421-1.647)$ & \\
\hline No & 1,083 (15.3) & $6,006(84.7)$ & 1 & \\
\hline
\end{tabular}

Values are presented as number (\%) unless otherwise indiceated.

$\mathrm{HR}$, hazard ratio; $\mathrm{Cl}$, confidence interval; CAS, carotid artery stenting; CEA, carotid endarterectomy. 
During the follow-up period, 2,607 patients in the CAS group (21.4\%) and 633 patients in the CEA group (16.3\%) died, corresponding to a cumulative incidence of 37.3\% (95\% $\mathrm{Cl}, 35.6-39.0)$ in the CAS group compared with $29.0 \%$ (95\% Cl, 26.3-31.7) in the CEA group. After the perioperative phase, 2,124 patients treated with CAS (17.4\%) and 412 patients (10.6\%) treated with CEA were admitted due to ischemic stroke, corresponding to a cumulative incidence of $24.9 \%$ (95\% Cl, 23.6-26.2) in the CAS group compared with $15.9 \%$
(95\% Cl, 14.0-17.9) in the CEA group. And, 162 patients treated with CAS (1.3\%) and 26 (0.7\%) patients with CEA were admitted due to cerebral hemorrhage corresponding to a cumulative incidence of $1.5 \%(95 \% \mathrm{Cl}, 1.4-2.0)$ in the CAS group compared with $0.9 \%$ (95\% Cl, 0.6-1.4) in the CEA group (Table 4). The incidence of major events during follow-up period was significantly lower in the CEA group than CAS group (Fig. 1).

The risk of cerebrovascular events was analyzed by comparing the age, symptomatic, and asymptomatic group.

Table 3. Multivariate Cox regression analysis of the overall HR related to the events

\begin{tabular}{|c|c|c|c|c|}
\hline \multirow{2}{*}{ Variable } & \multicolumn{2}{|c|}{ Ischemic stroke } & \multicolumn{2}{|c|}{ Cardiovascular death } \\
\hline & $\mathrm{HR}(95 \% \mathrm{Cl})$ & P-value & $\mathrm{HR}(95 \% \mathrm{Cl})$ & P-value \\
\hline Treatment & & $<0.0001$ & & $<0.0001$ \\
\hline CAS & $1.474(1.325-1.639)$ & & $1.569(1.338-1.841)$ & \\
\hline CEA & 1 & & 1 & \\
\hline Gender & & 0.4382 & & 0.0792 \\
\hline \multicolumn{5}{|l|}{ Male } \\
\hline \multicolumn{5}{|l|}{ Female } \\
\hline Age & & $<0.0001$ & & $<0.0001$ \\
\hline$\geq 80$ years & $1.410(1.255-1.585)$ & & $2.616(2.266-3.021)$ & \\
\hline$<80$ years & 1 & & 1 & \\
\hline Hypertension & & 0.8323 & & 0.7568 \\
\hline \multicolumn{5}{|l|}{ Yes } \\
\hline \multicolumn{5}{|l|}{ No } \\
\hline Diabetes mellitus & & 0.7391 & & 0.0139 \\
\hline Yes & & & $0.860(0.763-0.970)$ & \\
\hline No & & & 1 & \\
\hline Dyslipidemia & & $<0.0001$ & & $<0.0001$ \\
\hline Yes & $0.806(0.744-0.873)$ & & 0.699 (0.619-0.789) & \\
\hline No & 1 & & 1 & \\
\hline Atrial fibrillation & & 0.0111 & & $<0.0001$ \\
\hline Yes & $1.272(1.056-1.532)$ & & $1.852(1.469-2.333)$ & \\
\hline No & 1 & & 1 & \\
\hline Ischemic heart disease & & $<0.0001$ & & 0.0558 \\
\hline Yes & $0.794(0.719-0.877)$ & & & \\
\hline No & 1 & & & \\
\hline Chronic renal failure & & 0.987 & & $<0.0001$ \\
\hline Yes & & & $2.603(1.930-3.510)$ & \\
\hline No & & & 1 & \\
\hline Symptomatic & & $<0.0001$ & & $<0.0001$ \\
\hline Yes & 3.538 (3.207-3.904) & & $2.120(1.860-2.417)$ & \\
\hline No & 1 & & 1 & \\
\hline
\end{tabular}

HR, hazard ratio; Cl, confidence interval; CAS, carotid artery stenting; CEA, carotid endarterectomy. 
There was no statistically significant difference in the risk of death between CAS and CEA in patients with symptoms less than 70 years old and those older than 80 years. There was no statistical difference in the risk of death between CAS and CEA in asymptomatic patients between 70 and 80 years of age (Fig. 2). The subgroups without significant difference in cardiovascular death between CAS and CEA were either patients less than 70 years old regardless of symptoms, or asymptomatic patients older than 80 years (Fig. 3).

Table 4. Cumulative incidence at about 9 years and hazards for stroke and death in patients treated with CAS compared with CEA

\begin{tabular}{|c|c|c|c|c|c|c|}
\hline \multirow[b]{2}{*}{ Outcome } & \multicolumn{2}{|c|}{ CAS $(n=12,173)$} & \multicolumn{2}{|c|}{ CEA $(n=3,892)$} & \multicolumn{2}{|c|}{ HR $(95 \% \mathrm{CI})$ of CAS relative to CEA } \\
\hline & N & $\begin{array}{c}\text { Cum Inc (\%) } \\
(95 \% \mathrm{Cl})\end{array}$ & N & $\begin{array}{l}\text { Cum Inc (\%) } \\
(95 \% \mathrm{Cl})\end{array}$ & Unadjusted & $\begin{array}{l}\text { Adjusted for } \\
\text { confounders }\end{array}$ \\
\hline Ischemic stroke from day 28 & 2,141 & $24.9(23.6-26.2)$ & 412 & $15.9(14.0-17.9)$ & $1.82(1.639-2.020)$ & $1.474(1.325-1.639)$ \\
\hline Cerebral hemorrhage from day 28 & 162 & $1.5(1.4-2.0)$ & 26 & $0.9(0.6-1.4)$ & $2.210(1.460-3.344)$ & $2.026(1.322-3.106)$ \\
\hline Cardiovascular death & 1,006 & $12.2(11.3-13.1)$ & 184 & $7.3(6.1-8.6)$ & $1.836(1.570-2.148)$ & $1.569(1.338-1.841)$ \\
\hline Death & 2,607 & $37.3(35.6-39.0)$ & 633 & $29.0(26.3-31.7)$ & $1.434(1.315-1.565)$ & $1.282(1.173-1.400)$ \\
\hline
\end{tabular}

CAS, carotid artery stenting; CEA, carotid endarterectomy; HR, hazard ratio; Cl, confidence interval; Cum Inc, cumulative incidence.

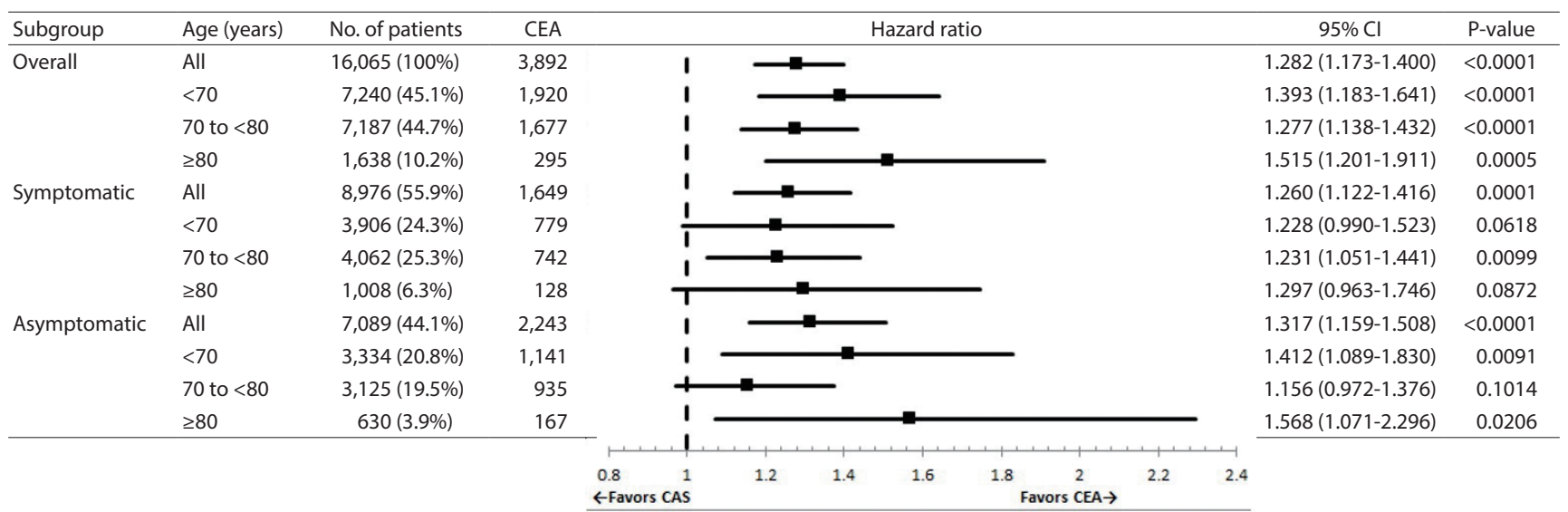

Fig. 2. Adjusted hazard ratio for all-cause mortality in patients treated with CAS (relative to patients treated with CEA). CEA, carotid endarterectomy; $\mathrm{Cl}$, confidence interval; CAS, carotid artery stenting.

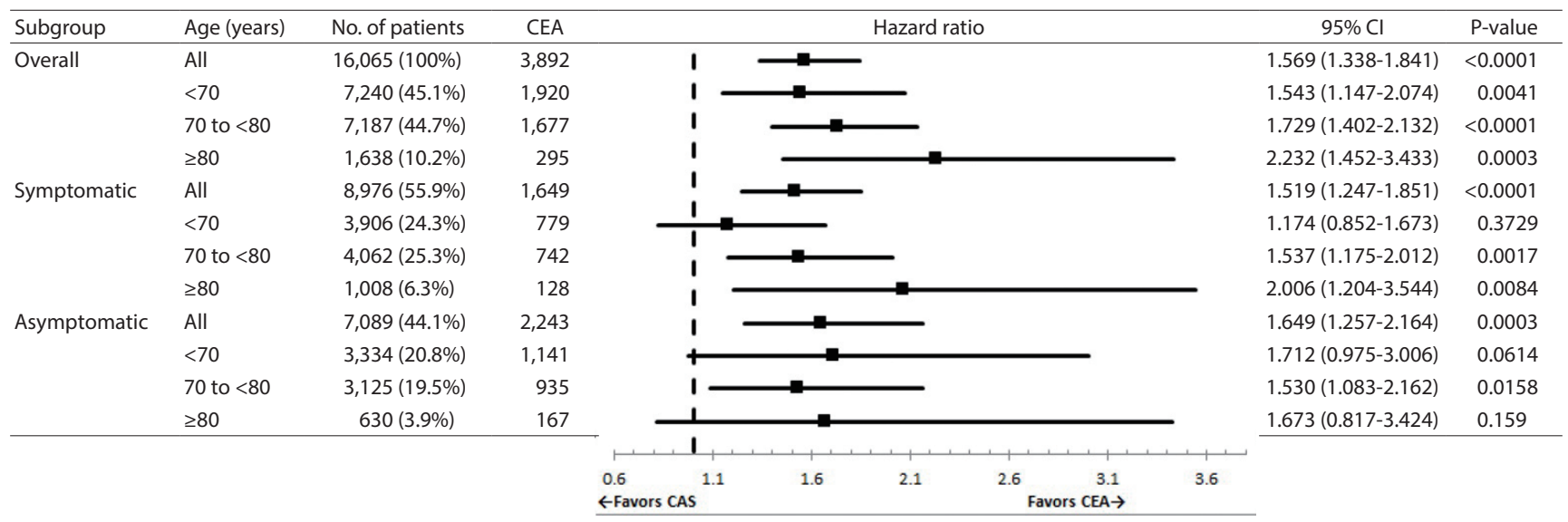

Fig. 3. Adjusted hazard ratio for cardiovascular death in patients treated with CAS (relative to patients treated with CEA). CEA, carotid endarterectomy; $\mathrm{Cl}$, confidence interval; CAS, carotid artery stenting. 


\section{DISCUSSION}

The prognosis of patients who received carotid revascularization in this study differed between CAS and CEA groups. These results are similar to those of previous studies and meta-analysis. ${ }^{6,12}$ Because of the lack of evidence, current guidelines recommend CAS as an alternative to CEA in limited patients. ${ }^{3,13}$ CAS is indicated as an alternative to CEA for symptomatic patients with high risk comorbidities or anatomy. Age is also a factor to be considered in determining treatment options. In a previous study, the high risk group of CEA was defined as those individuals with severe comorbidities, technical factors, and old age (>80 years). ${ }^{14}$ Guidelines in America and Europe recommend CAS in symptomatic patients less than 70 years of age, because periprocedural complications and long-term ipsilateral stroke recurrence are not different between CAS and CEA. . $^{15,16}$

In this study, mean age and proportion of symptomatic patients and males was not different from those of previous studies. ${ }^{17,18}$ The incidence of hypertension, dyslipidemia, ischemic heart disease, and renal failure in this study was lower than previous studies, but diabetes mellitus was higher. ${ }^{7,17,19}$ Patients who received CAS were less likely to have chronic comorbidities unlike a previous study. ${ }^{7}$ Unlike CEA, which is mainly performed in tertiary hospitals, CAS is more widely performed in Korean non-tertiary hospitals than in Korean tertiary hospitals. Therefore, it is possible that CAS can be performed more than CEA, and that there are fewer comorbidities in the CAS group due to the characteristics of non-tertiary hospitals with relatively less severe patients. The factors related to long-term mortality were age, diabetes mellitus, renal insufficiency, symptomatic status, and statin use in previous studies. ${ }^{20}$ Similar to a previous study, old age (>80 years), symptomatic status, and renal failure were the most significant risk factors associated with long-term allcause mortality and cardiovascular death in this study.

Long-term all-cause mortality was not different significantly between CAS and CEA in the meta-analysis of a randomized controlled study and nationwide cohort study. ${ }^{6,17}$ However, there was difference in the all-cause mortality between the groups in this study like a prior multi-center cohort study. The long-term risk of ischemic stroke after carotid revascularization was higher in the CAS group than CEA group in this study, and the HR was similar to the result of a meta-analysis and nationwide cohort study. ${ }^{6}$ The incidence of ischemic stroke after carotid revascularization in this study was higher than those of previous studies, but the long-term mortality was similar. The incidence of cerebral hemorrhage after carotid stenting was reported about $0.85-4.4 \%$ from previous population-based studies and it was 2-6 fold higher among CAS relative to CEA. ${ }^{21,22}$ Although this study was based on long-term follow-up, the incidence of cerebral hemorrhage and the risk of CAS were similar to those of the previous studies. In this study, information regarding death is highly reliable, but data regarding the other outcomes are not. Even if no neurological symptoms have occurred, there may be some patients who were admitted with the ischemic stroke code to perform brain magnetic resonance imaging. It is possible that the incidence of ischemic stroke has been overestimated.

Long-term outcomes were studied in the sub-group analysis according to the presence of symptom and age. All-cause mortality and cardiovascular death were not significantly different between CAS and CEA in young and symptomatic patients. This result is consistent with current guidelines. ${ }^{2,3}$ Also, all-cause mortality was not different between CAS and CEA in older symptomatic patients, and cardiovascular death was not different in older asymptomatic patients. These results may support CAS as an alternative measure in elderly patients at high risk of CEA.

The limitation of this study lies in the analysis of the claim database. There is possibility that incidence of comorbidities in this study is lower than in real-world data. The proportion of symptomatic patients is similar to previous studies, but it may be underestimated also due to lack of clinical information. Because admission by specific code was limited to occurrence of ischemic stroke or cerebral hemorrhage, it is possible that the frequency of cerebrovascular events were overestimated. There was no information about re-stenosis. In Korea, CAS is sometimes preferred rather than CEA without medical evidence, and there was no clinical information about anatomical risk factors related to treatment modality choice.

The strengths of our study include the nationwide, large real-world data, including high-confidence mortality data. Unlike previous studies, this study analyzed many patients who underwent CAS rather than CEA. CAS generally did not show better results than CEA, but a similar prognosis was found in some of the patients using the recommended guidelines. 


\section{CONCLUSION}

In this nationwide data, the all-cause mortality rate was higher in patients with CAS over the long term. However, the long-term prognosis of CAS and CEA was similar in young symptomatic patients. In the future, a prospective study should be performed to select appropriate treatment for each patient. Until further evidence of CAS is established through prospective studies, CAS should be performed in selected patients according to current guidelines.

\section{Acknowledgments}

This study was supported by the Korean Society of Interventional Neuroradiology (KSIN) research grant 2018.

\section{REFERENCES}

1. Flaherty ML, Kissela B, Khoury JC, Alwell K, Moomaw CJ, Woo D, et al. Carotid artery stenosis as a cause of stroke. Neuroepidemiology 2013;40:36-41

2. Naylor AR, Ricco JB, de Borst GJ, Debus S, de Haro J, Halliday A, et al. Editor's choice - management of atherosclerotic carotid and vertebral artery disease: 2017 clinical practice guidelines of the european society for vascular surgery (ESVS). Eur J Vasc Endovasc Surg 2018;55:3-81

3. Kernan WN, Ovbiagele B, Black HR, Bravata DM, Chimowitz MI, Ezekowitz MD, et al. Guidelines for the prevention of stroke in patients with stroke and transient ischemic attack: a guideline for healthcare professionals from the American Heart Association/American Stroke Association. Stroke 2014;45:2160-2236

4. Abbott AL, Paraskevas Kl, Kakkos SK, Golledge J, Eckstein HH, Diaz-Sandoval $\sqcup$, et al. Systematic review of guidelines for the management of asymptomatic and symptomatic carotid stenosis. Stroke 2015;46:3288-3301

5. Suh SH. The annual trends between neurointerventional and neurosurgical procedures in korea: analysis using hira data from 2010 to 2016. Neurointervention 2017;12:77-82

6. Li Y, Yang JJ, Zhu SH, Xu B, Wang L. Long-term efficacy and safety of carotid artery stenting versus endarterectomy: a meta-analysis of randomized controlled trials. PLoS One 2017;12:e0180804

7. Columbo JA, Martinez-Camblor P, MacKenzie TA, Staiger DO, Kang R, Goodney PP, et al. Comparing long-term mortality after carotid endarterectomy vs carotid stenting using a novel instru- mental variable method for risk adjustment in observational time-to-event data. JAMA Netw Open 2018;1:e181676

8. Sundararajan V, Quan H, Halfon P, Fushimi K, Luthi JC, Burnand B, et al. Cross-national comparative performance of three versions of the ICD-10 charlson index. Med Care 2007;45:1210-1215

9. Quan H, Sundararajan V, Halfon P, Fong A, Burnand B, Luthi JC, et al. Coding algorithms for defining comorbidities in ICD-9-cm and ICD-10 administrative data. Med Care 2005;43:1130-1139

10. Mantese VA, Timaran CH, Chiu D, Begg RJ, Brott TG; CREST Investigators. The carotid revascularization endarterectomy versus stenting trial (CREST): stenting versus carotid endarterectomy for carotid disease. Stroke 2010;41(10 Suppl):S31-S34

11. Ahn SV. Estimating the incidence of acute myocardial infarction and stroke based on the National Health Insurance claims data in Korea. http://www.prism.go.kr/homepage/entire/retrieveEntireDetail.do?research_id=1351000-201600354. Accessed December 10, 2018

12. Morris DR, Ayabe K, Inoue T, Sakai N, Bulbulia R, Halliday A, et al. Evidence-based carotid interventions for stroke prevention: state-of-the-art review. J Atheroscler Thromb 2017;24:373-387

13. Aboyans V, Ricco JB, Bartelink MEL, Björck M, Brodmann M, Cohnert T, et al. 2017 ESC guidelines on the diagnosis and treatment of peripheral arterial diseases, in collaboration with the European Society for Vascular Surgery (ESVS): document covering atherosclerotic disease of extracranial carotid and vertebral, mesenteric, renal, upper and lower extremity arteriesEndorsed by: the European Stroke Organization (ESO) the task force for the diagnosis and treatment of peripheral arterial diseases of the European Society Of Cardiology (ESC) and of the European Society for Vascular Surgery (ESVS). Eur Heart J 2018;39:763-816

14. Yadav JS, Wholey MH, Kuntz RE, Fayad P, Katzen BT, Mishkel GJ, et al. Protected carotid-artery stenting versus endarterectomy in high-risk patients. N Engl J Med 2004;351:1493-1501

15. Blackshear JL, Cutlip DE, Roubin GS, Hill MD, Leimgruber PP, Begg RJ, et al. Myocardial infarction after carotid stenting and endarterectomy: results from the carotid revascularization endarterectomy versus stenting trial. Circulation 2011;123:25712578

16. Naylor AR. Endarterectomy versus stenting for stroke prevention. Stroke Vasc Neurol 2018;3:101-106

17. Jonsson M, Lindström D, Gillgren P, Wanhainen A, Malmstedt J. Long-term outcome after carotid artery stenting: a population-based matched cohort study. Stroke 2016;47:2083-2089

18. Egashira Y, Yoshimura S, Sakai N, Enomoto Y; Japanese Registry of Neuroendovascular Therapy Investigators. Real-world experience of carotid artery stenting in japan: analysis of 7,134 cases 
from JR-NET1 and 2 nationwide retrospective multi-center registries. Neurol Med Chir (Tokyo) 2014;54:32-39

19. Brott TG, Howard G, Roubin GS, Meschia JF, Mackey A, Brooks W, et al. Long-term results of stenting versus endarterectomy for carotid-artery stenosis. N Engl J Med 2016;374:1021-1031

20. Volkers EJ, Algra A, Kappelle LJ, Greving JP. Prediction models for clinical outcome after a carotid revascularisation procedure: a systematic review. Eur Stroke J 2018;3:57-65
21. Hussain MA, Alali AS, Mamdani M, Tu JV, Saposnik G, Salata K, et al. Risk of intracranial hemorrhage after carotid artery stenting versus endarterectomy: a population-based study. J Neurosurg 2018;129:1522-1529

22. McDonald RJ, Cloft HJ, Kallmes DF. Intracranial hemorrhage is much more common after carotid stenting than after endarterectomy: evidence from the National Inpatient Sample. Stroke 2011;42:2782-2787 